\title{
Numerical Analysis on the Oscillator of External Stimulation and Self-Excited
}

\author{
Junlong Li, Jiupeng Zou \\ Schoolof Chemical Machinery and Safety, Dalian University of Technology, Dalian, China \\ Email: junlong_work@163.com, zoujp@dlut.edu.cn \\ Received 14 July 2016; accepted 8 August 2016; published 15 August 2016
}

\begin{abstract}
In this article, the performance of the novel external stimulation oscillator and the optimized selfexcited oscillator has been investigated by CFD numerical simulation. The efficiency and stimulation mechanism of the two kinds of oscillators were analyzed in numeric form. The cycle proportion of wall-attached jet switching time was calculated separately at different operating frequency. Additionally the reason for the difference of two oscillators was analyzed and explained.
\end{abstract}

Keywords

Jet Oscillation, Stimulation, Efficiency, CFD

\section{Introduction}

Fluidic oscillator as a fluid control device has been developed recent years. The oscillation jet of compressible fluid has been used in microfluidic mixer [1], medical application [2], thermal separators [3] and so on. The static gas wave refrigerator relies on the periodic deflection of jet to distribute the jet into gas wave tubes [4].

Using the Coanda effect [5] and the wall-attached switching mechanism, the fluidic oscillator generates a pulsed jet. According to the difference of stimulation method, it involves the conventional self-excited oscillator and the novel external stimulation oscillator [6]. Self-exited bistable wall-attached jet oscillator mainly involves feedback jet oscillator, sonic jet oscillator and resonant jet oscillator. The previous study on self-exited jet oscillator [7] [8] almost all focused on the oscillator geometric structure and the influencing factor of oscillating frequency. The researches on efficiency characteristics were rare to look up. On account of the constraint of structural characteristics, the feedback oscillator loses a lot of energy on where the main jet distributes and it is difficult to reduce. Resonant oscillator has the similar structure with sonic oscillator, but the oscillating frequency is hard to regulate. In self-excited oscillators, sonic oscillator has a relatively high total pressure of outlet. Therefore, the sonic oscillator occupies a dominant position in the self-excited oscillators.

Based on the previous research about the oscillator, the sonic oscillator was optimized to obtain a higher total pressure of outlet. Then the oscillator performance and stimulation characteristic were compared with the novel external stimulation oscillator.

\section{Physical Model and Computational Method}

Many two-dimensional and three-dimensional simulations suggest that the difference of node parameters is

How to cite this paper: Li, J.L. and Zou, J.P. (2016) Numerical Analysis on the Oscillator of External Stimulation and SelfExcited. Journal of Applied Mathematics and Physics, 4, 1494-1498. http://dx.doi.org/10.4236/jamp.2016.48156 
within 2\%. Two-dimensional simulation can save a lot of time. Figure 1(a) shows the simple structure of the external stimulation oscillator and Figure 1(b) shows the structure of sonic self-excited oscillator [9]. The computational structured grids were generated by Gambit, and shown in Figure 2(a) and Figure 2(b).

The FVM (Finite Volume Method) was used to discretize the governing equations, the Roe flux difference splitting scheme was adopted for the convection term and the central difference scheme for dissipation term. Second order implicit time step was chosen for unsteady integrals [10].

The total pressure of the nozzle inlet was $P_{i}=0.36 \mathrm{MPa}$, channel outlet $P_{o}=0.18 \mathrm{MPa}$, and the expansion ratio $\varepsilon=P_{i} / P_{o}=2$. The peak value of the total pressure of stimulating flow was $0.36 \mathrm{MPa}$, and the valley value was $0.18 \mathrm{MPa}$. The waveform of the stimulating flow was trapezoidal wave by programming the incentive function (UDF). Two oscillators used the same nozzle width: $W=2.5 \mathrm{~mm}$, and the same angle of splitter: $\theta=20^{\circ}$. Other structure parameters were showed in Table 1.

\section{Results and Discussion}

\subsection{The Total Pressure Retention Rate of Different Oscillatory Types}

$K$, the ratio of the total pressure of channel outlet to total pressure of nozzle inlet, denotes the total pressure retention rate. The higher total pressure retention rate of the oscillation jet means the less the energy loss. The $K$ of the general and the optimized oscillators are shown in Table 2. Table 2 suggests that the $K$ of the optimized sonic self-excited oscillator was increased by $12 \%$, but still less than that of external stimulation oscillator.

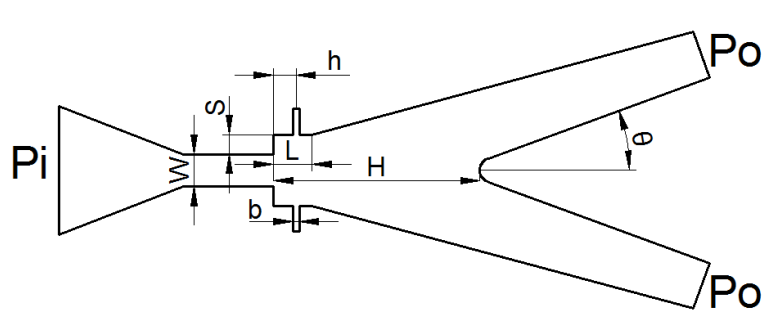

(a)

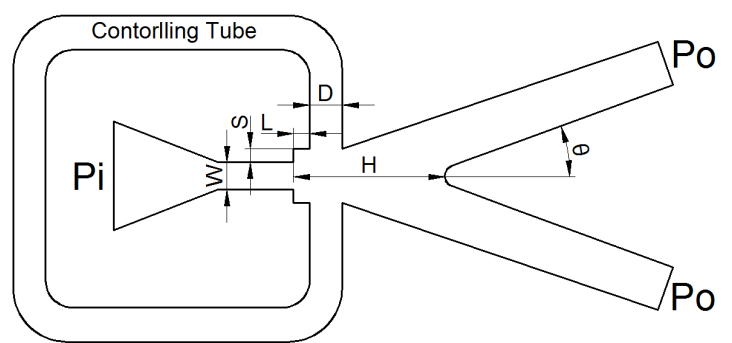

(b)

Figure 1. Structures of the two oscillators. $W$-the width of nozzle exit; $H$-the distance between the nozzle exit and the splitter; $\theta$ - the angle of splitter; $S$ - the position distance; $b$ - the width of the external stimulation orifice; $D$-the width of the self-excited orifice; $L$-the length of straight wall; $h$-the distance between the nozzle exit and the external stimulation orifice; $L_{C}$ - the length of controlling tube.

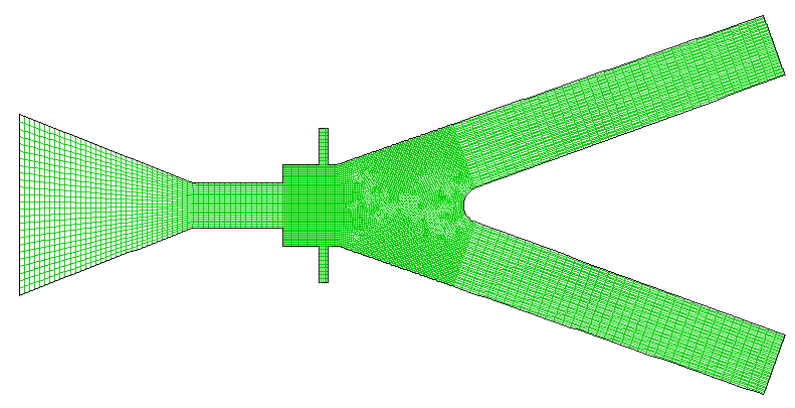

(a)

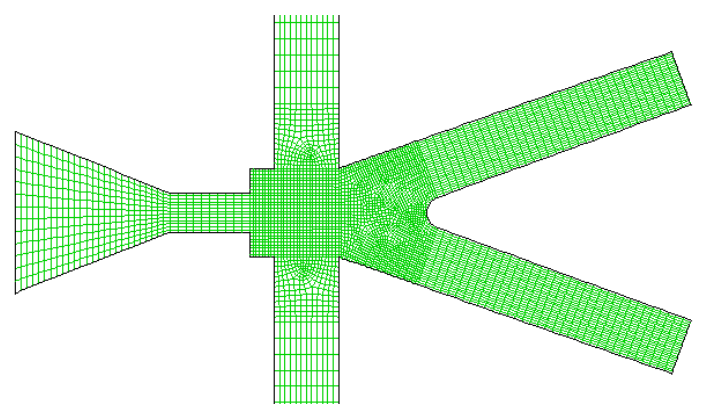

(b)

Figure 2. Computational grids of the two oscillators.

Table 1. The structure parameters of thetwo oscillators after optimized.

\begin{tabular}{ccccccc}
\hline Structure parameter & $S(\mathrm{~mm})$ & $L(\mathrm{~mm})$ & $h(\mathrm{~mm})$ & $b(\mathrm{~mm})$ & $D(\mathrm{~mm})$ & $H(\mathrm{~mm})$ \\
\hline Sonic oscillator & 1.5 & 1.5 & - & - & 4 & 11 \\
External stimulation oscillator & 1 & 3 & 2.25 & 0.5 & - & 10 \\
\hline
\end{tabular}


Table 2. The total pressure retention rate of the different oscillatory types.

\begin{tabular}{ccccc}
\hline \multirow{2}{*}{$\begin{array}{c}\text { Efficiency } \\
\text { Parameter }\end{array}$} & \multicolumn{4}{c}{ Category of Oscillators } \\
\cline { 2 - 5 } & $\begin{array}{c}\text { General Sonic } \\
\text { Self-excited }\end{array}$ & $\begin{array}{c}\text { Optimized Sonic } \\
\text { Self-excited }\end{array}$ & $\begin{array}{c}\text { General External } \\
\text { Stimulation }\end{array}$ & $\begin{array}{c}\text { Optimized External } \\
\text { Stimulation }\end{array}$ \\
\hline$K$ & $70.4 \%$ & $82.2 \%$ & $82.6 \%$ & $89.4 \%$ \\
\hline
\end{tabular}

Figure 3 shows the total pressure waveform of main jet and stimulating flow in two oscillators at $50 \mathrm{~Hz}$ operating frequency. The stimulating flow in self-excited oscillator was the distributary of the main jet, which had a great energy loss. The average total pressure of stimulating flow was far below that of main jet, as shown in Figure 3(a). The acceleration process of stimulating flow produced the effect of ejector. The intensely momentum exchange between stimulating flow and main jet, expended kinetic energy of the main jet in quantity. It would reduce the energy of the main jet to a large extent (Figure 3(b)).

On the contrary in external stimulation oscillator, the static pressure of stimulating inlet is higher than that of the downstream. The stimulating flow could be accelerated by self-expansion. So it scarcely consumed the energy of main jet. Therefore, the total pressure loss was much less than the self-excited oscillator as shown in Figure 3(b).

As Figure 3(a) shows, besides the difference of total pressure, the waveform trailing edge fell off early, which caused the main jet to be in a state of suspension. The suspension time of main jet will be discussed in 3.2.

\subsection{The Cycle Proportion of Wall-Attached Jet Switching Time}

$R$, the ratio of the suspension time of main jet to the cycle time, denotes the cycle proportion of wall-attached jet switching time. The wall-attached main jet switching process is under the boost and momentum of the stimulating flow. Evaluation of the pros and cons of the switching process depends on the adherence behavior of main jet and the duration of swing. An increase in switching time keeps the oscillator in bi-pass state, which means turbulence and increased loss. Therefore, the smaller the $R$ is, the less the energy loss is.

In order to change the oscillation frequency of sonic oscillator, the length of controlling tube was adjusted (Table 3). Then the $R$ was calculated after simulation. Results are shown in Figure 4. The $R$ of sonic self-excited oscillator is all beyond that of external stimulation oscillator. At low frequency, although the $R$ of self-excited oscillator is small, still twice that of the external stimulation oscillator. And with the increase of oscillation frequency, there is a significant upward trend.

Figure 5 shows the relationship of the stimulating flow mass characteristic in two kinds of oscillators. The stimulating flow of the external stimulation oscillator has the explosive and sustained characteristic. The explosiveness enables wall-attached jet to switch the wall suddenly without the process of falling from the wall. The sustained characteristic can continue pressing and promoting stimulation, which keeps the subsequent main jet completely attaching to the wall. However, the stimulating flow of the self-excited oscillator does not have the above characteristics. As Figure 5 shows, the stimulating flow in self-excited oscillator increased gradually and weakened gradually, which resulted in that the wall-attached jet had no sustained momentum and differential pressure. So the main jet would fall off from the wall. In this condition, to make the subsequent main jet attached to the wall, increasing the position distance of structure is the only way. However, this would increase the energy loss in upstream of the main jet. As a result, the switching time of the wall-attached jet in external stimulation oscillator is much shorter than that of the self-excited oscillator.

\section{Conclusions}

Due to the difference of stimulating characteristics, the efficiency of external stimulation oscillator is higher than that of distributary self-excited oscillator by nearly $10 \%$, and the energy loss rate is reduced by almost $50 \%$ relatively.

The stimulating flow of distributary self-excited oscillator has no explosive and sustained characteristic. It must rely on the entrainment of the main jet to re-accelerate. So this process loses a large amount of kinetic energy. Unlike self-excited oscillation, stimulating flow of external oscillation drains from the same gas source with main jet. It makes the stimulating flow have the approximate total pressure with main jet. So a self-expansion influx with main jet would not consume too much energy. 


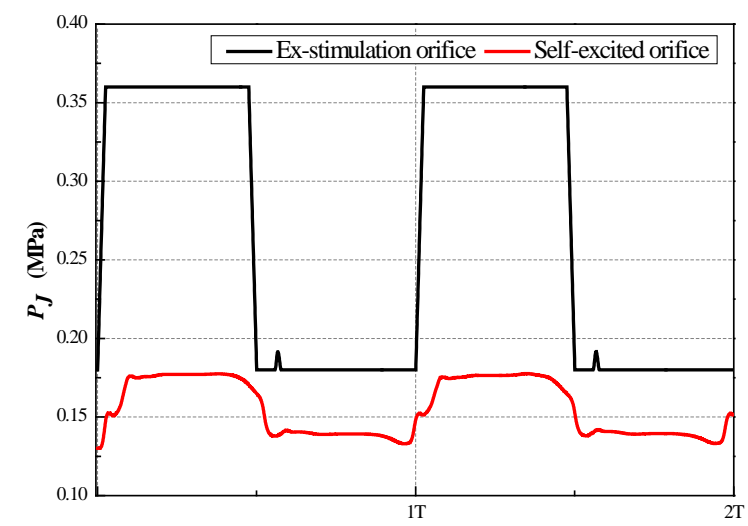

(a)

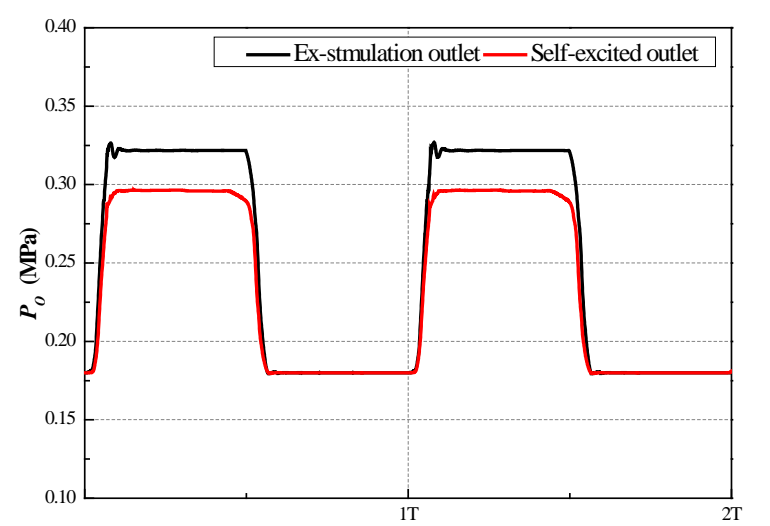

(b)

Figure 3. The total pressure waveform of stimulating orifice and channel outlet.

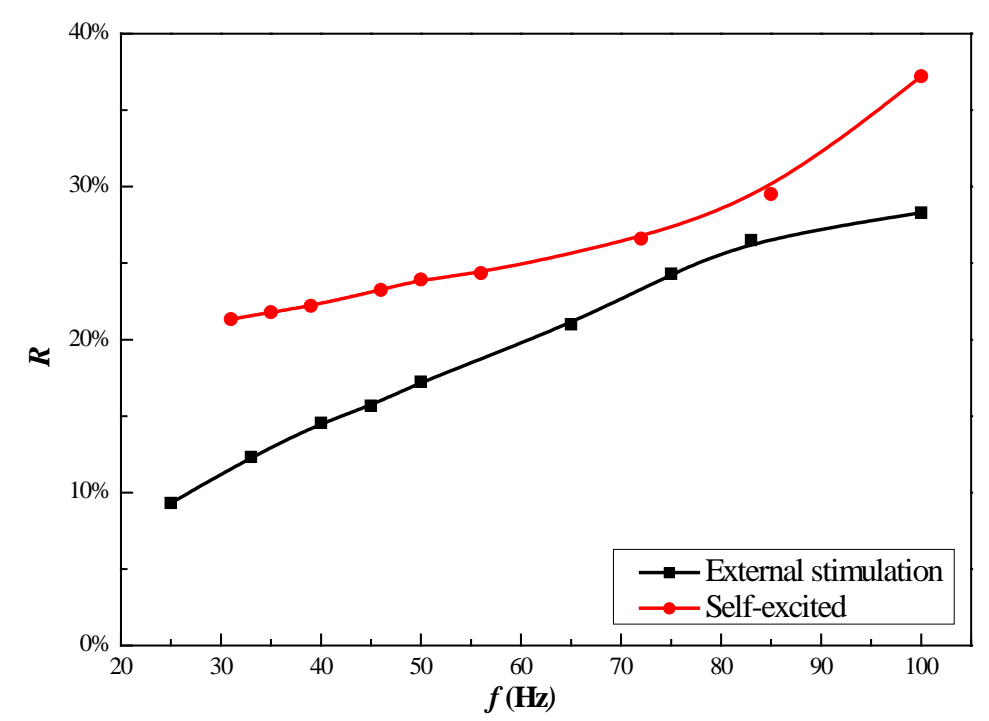

Figure 4. The graph of the cycle proportion of wall-attached jet switching time.

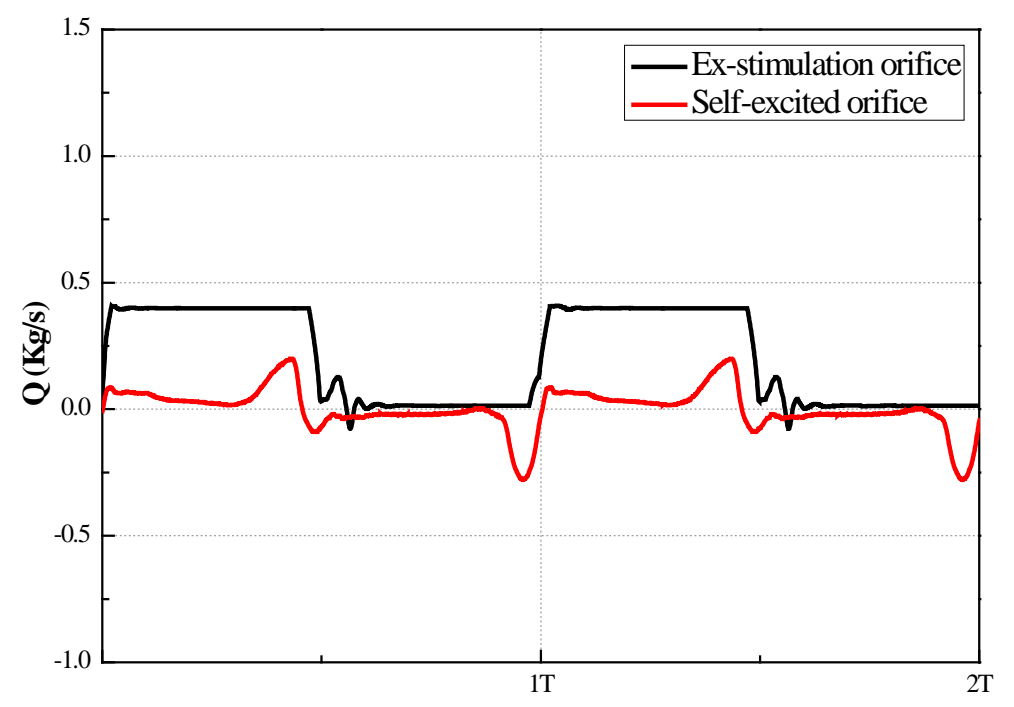

Figure 5. The mass flow rate waveform of oscillator stimulating orifice. 
Table 3. The controlling tube length and oscillation frequency of self-excited sonic oscillator.

\begin{tabular}{cccccccccc}
\hline$L_{c}(\mathrm{~m})$ & 1 & 1.3 & 1.5 & 2 & 2.3 & 2.5 & 3 & 3.5 & 4 \\
\hline$f(\mathrm{~Hz})$ & 100 & 85 & 72 & 56 & 50 & 46 & 39 & 35 & 30 \\
\hline
\end{tabular}

The jet switching speed is relatively slow in the distributary self-excited oscillator. At different oscillation frequencies, the cycle proportion of wall-attached jet switching time of self-excited oscillator are all higher than that of external stimulation oscillator.

The results from numerical simulation and analysis indicate that the novel external stimulation oscillator has the higher efficiency and the better stimulation performance.

\section{Acknowledgements}

This work was financially supported by the National Natural Science Foundation of China (51276026).

\section{References}

[1] Xu, C. and Chu, Y.F. (2015) Experimental Study on Oscillating Feedback Micromixer for Miscible Liquids Using the Coanda Effect. AIChE Journal, 61, 1054-1063. http://dx.doi.org/10.1002/aic.14702

[2] Gebhard, U., Hein, H., Just, E. and Ruther, P. (1997) Combination of a Fluidic Micro-Oscillator and Micro-Actuator in LIGA-Technique for Medical Application. International Conference on Solid State Sensors and Transducers of the IEEE, Chicago, June 16-19 1997. http://dx.doi.org/10.1109/sensor.1997.635211

[3] Liang, S.B., Li, X.L. and Ma, H.B. (2003) Thermoacoustic Power Effect on the Refrigeration Performance of Thermal Separators. Cryogenics, 43, 493-500. http://www.sciencedirect.com/science/article/pii/S0011227503001267 http://dx.doi.org/10.1016/S0011-2275(03)00126-7

[4] Ji, X.H. and Liu, W. (2001) The Influential Factors of Isentropic Efficiency of Gas Wave Refrigerator. Journal of Liaoyang Petrochemical College, 4, 12.

[5] Matsuo, S., Setoguchi, T., Kudo, T. and Yu, S. (1998) Study on the Characteristics of Supersonic Coanda Jet. Journal of Thermal Science, 7, 165-175. http://link.springer.com/article/10.1007/s11630-998-0012-2 http://dx.doi.org/10.1007/s11630-998-0012-2

[6] Wang, J. (2014) Performance Analysis of Outside Stimulating Jet Oscillator. M.S. Thesis, Dalian University of Technology, Dalian.

[7] Chen, S.T., Hu, D.P., Chen, Z.Z. and Dai, Y.Q. (2007) Switch of Jet Flow in a Sonic Oscillator. Proceedings of the Fifth International Symposium on Fluid Power Transmission and Control, Chinwangtao, June 2007.

[8] Hu, D.P., Chen, Z.Z., Dai, Y.Q. and Chen, S.S. (2007) Effects of Geometrical Size on Flow Characteristics of Jet in Sonic Oscillator. Journal of Chemical Industry and Engineering (China), 58, 1180.

[9] Xin, L. (2010) Study on the Oscillation of Sonic Oscillator and Application. M.S. Thesis, Dalian University of Technology, Dalian.

[10] Wang, F.J. (2004) Computational Fluid Dynamics Analysis: Theory and Application of CFD Software. Tsinghua University Press, Beijing, 26-28, 39-44. 


\section{Submit or recommend next manuscript to SCIRP and we will provide best service for you:}

Accepting pre-submission inquiries through Email, Facebook, LinkedIn, Twitter, etc.

A wide selection of journals (inclusive of 9 subjects, more than 200 journals)

Providing 24-hour high-quality service

User-friendly online submission system

Fair and swift peer-review system

Efficient typesetting and proofreading procedure

Display of the result of downloads and visits, as well as the number of cited articles

Maximum dissemination of your research work

Submit your manuscript at: http://papersubmission.scirp.org/ 